University of Nebraska - Lincoln

DigitalCommons@University of Nebraska - Lincoln

Faculty Publications from the Harold W. Manter Laboratory of Parasitology

1999

\title{
Six New Eimeria Species from Vespertilionid Bats from North America
}

Donald W. Duszynski

University of New Mexico, eimeria@unm.edu

Damien T. Scott

University of New Mexico

Jacqee Aragon

University of New Mexico

Ashley Leach

University of New Mexico

Travis Perry

University of New Mexico

Follow this and additional works at: https://digitalcommons.unl.edu/parasitologyfacpubs

Part of the Parasitology Commons

Duszynski, Donald W.; Scott, Damien T.; Aragon, Jacqee; Leach, Ashley; and Perry, Travis, "Six New Eimeria Species from Vespertilionid Bats from North America" (1999). Faculty Publications from the Harold W. Manter Laboratory of Parasitology. 151.

https://digitalcommons.unl.edu/parasitologyfacpubs/151

This Article is brought to you for free and open access by the Parasitology, Harold W. Manter Laboratory of at DigitalCommons@University of Nebraska - Lincoln. It has been accepted for inclusion in Faculty Publications from the Harold W. Manter Laboratory of Parasitology by an authorized administrator of DigitalCommons@University of Nebraska - Lincoln. 


\title{
SIX NEW EIMERIA SPECIES FROM VESPERTILIONID BATS OF NORTH AMERICA
}

\author{
Donald W. Duszynski, Damien T. Scott, Jacqee Aragon, Ashley Leach, and Travis Perry
}

Department of Biology, The University of New Mexico, Albuquerque, New Mexico 87131

\begin{abstract}
Twenty species of bats (Molossidae, Vespertilionidae) were collected from California, New Mexico, Oregon, South Carolina, Utah, and Baja California Norte (Mexico), and 29 of 404 (7\%) animals, including Antrozous pallidus, Eptesicus fuscus, Myotis auriculus, Myotis californicus, Myotis ciliolabrum, Myotis evotis, Myotis lucifugus, Myotis thysanodes, Myotis vivesi, Myotis volans, Myotis yumanensis, and Nycticeius humeralis were infected with Eimeria spp., which represent 6 new species. Sporulated oocysts of a new species from A. pallidus are subspheroidal, $24.8 \times 21.6(22-27 \times 19-24) \mu \mathrm{m}$ with a polar granule and a large globular residuum. The oocyst wall is sculptured, with 2 layers, $\sim 1.5$ thick. Ovoidal sporocysts are $11.5 \times 7.8(9-$ $13 \times 7-10) \mu \mathrm{m}$, with Stieda body and residuum of many large granules. Sporulated oocysts of a new species from M. californicus are subspheroidal, $20.7 \times 18.2(19-23 \times 16-20) \mu \mathrm{m}$, with 1-7 tiny polar granules, but without oocyst residuum. The oocyst wall is rough, with 2 layers, $\sim 1.4$ thick. Ovoidal sporocysts are $11.2 \times 7.3(10-12 \times 7-8) \mu \mathrm{m}$, with Stieda body and a globular residuum. Sporulated oocysts of a second new species from $M$. californicus are subspheroidal, $23.1 \times 20.7(20-26 \times 19-23)$ $\mu \mathrm{m}$, with residuum and 1 polar granule, but a micropyle is absent. The oocyst wall is rough with 2 layers, $\sim 1.5$ thick. Ovoidal sporocysts are $12.5 \times 7.2(11-14 \times 7-8) \mu \mathrm{m}$, with a Stieda body and residuum. Sporulated oocysts of a new species from $M$. ciliolabrum are subspheroidal, $24.9 \times 20.1(18-27 \times 17-23) \mu \mathrm{m}$, with 1-2 polar granules, but without micropyle and residuum. The oocyst wall is rough with 2 layers, $\sim 1.5$ thick. Ellipsoidal sporocysts are $12.5 \times 9.0(8-14 \times 7-10) \mu \mathrm{m}$, with Stieda and substieda bodies and residuum. Sporulated oocysts of a new species from M. evotis are subspheroidal, $21.3 \times 18.6(20-24 \times$ 15-20) $\mu \mathrm{m}$, with a prominent polar granule, but without micropyle and residuum. The oocyst wall is smooth with 2 layers, $\sim 1.0$ thick. Ovoidal sporocysts are $12.2 \times 8.0(11-13 \times 7.5-9) \mu \mathrm{m}$, with Stieda and substieda bodies and residuum. Sporulated oocysts of the new species from $N$. humeralis are subspheroidal, $22.4 \times 18(21-24 \times 17-20) \mu \mathrm{m}$, with 1-3 polar granules, but residuum and micropyle are absent. The oocyst wall is lightly sculptured with 2 layers, $\sim 1.4$ thick. Ovoidal sporocysts are $10.9 \times 7.7(9-$ $12 \times 6-8) \mu \mathrm{m}$, with Stieda body and residuum. Sporulated oocysts of E. pilarensis Scott and Duszynski, 1997 and those of at least 12 other morphological forms were seen in the other infected bats; these latter forms were seen in too few numbers to be adequately described as new species.
\end{abstract}

The number of Eimeria spp. in bats continues to increase as more surveys are conducted that specifically search for these parasites. For example, in 1996 there were only 14 Eimeria spp. known from this host group; however, with the addition of the 6 species described here, there now are 25 known species, an increase in our knowledge of coccidia biodiversity from bats of 48\% since 1996 (Duszynski, 1997; Scott and Duszynski, 1997; Duszynski et al., 1999). This diversity is still much lower than the $>400$ eimerian species described from rodents (Levine and Ivens, 1990; Scott and Duszynski, 1997), but as new surveys are done, indications are that bats may be a good source for many undescribed eimerian parasites.

\section{MATERIALS AND METHODS}

Hosts were collected as part of chiropteran surveys in New Mexico (1979-1980, 1996-1997), California (1979-1980), Oregon (1979), South Carolina (1996), Utah (1996), and Baja California Norte, Mexico (1980); bats were caught using mist nets, trip lines, modified harp traps, and by hand. Feces were taken from the intestines of bats that were collected for voucher specimens. All voucher specimens, including symbiotype hosts (Frey et al., 1992) were deposited in the Museum of Southwestern Biology (MSB), the University of New Mexico (UNM). Bats that were to be released were held in captivity until they defecated into individual containers. The procedures for preserving fecal material in $2 \%$ aqueous (w/v) $\mathrm{K}_{2} \mathrm{Cr}_{2} \mathrm{O}_{7}$ solution, and isolating, measuring and photographing oocysts were described in detail elsewhere (Duszynski and Wilber, 1997), although much of this work was completed before their procedures were published. Photosyntypes (see Results and Bandoni and Duszynski [1988]) of sporulated oocysts were deposited in the U.S. National Parasite Collection (USNPC), Beltsville, Maryland. Oocysts were $<200$ days old when measured. All measurements are in $\mu \mathrm{m}$ with the mean in parentheses following the size ranges.

Received 10 August 1998; revised 16 November 1998; accepted 16 November 1998.

\section{RESULTS}

Of 404 bats ( 2 families, 20 species) examined for coccidia, 29 (7\%) had oocysts of Eimeria spp. in their feces (Table I). Seven host spp., Eptesicus fuscus, Myotis auriculus, Myotis evotis, Myotis lucifugus, Myotis thysanodes, Myotis vivesi, and Myotis volans had small numbers of oocysts in their feces; some of these oocysts later sporulated in our laboratory (see Materials and Methods), and this enabled us to identify at least 12 more different structural types (=morphotypes) that we believe represent undescribed Eimeria spp.; however, following the suggestion of Duszynski and Wilber (1997), there were not sufficient numbers present to allow a complete description of any of them. Eimeria pilarensis Scott and Duszynski, 1997, previously reported in Myotis ciliolabrum (Taos Co., New Mexico) and in Myotis yumanensis (San Luis Obispo Co., California; Catron Co., New Mexico), was found in 3/23 (13\%) $M$. yumanensis from Socorro Co., New Mexico, but not in 67 specimens of $M$. ciliolabrum from 5 localities in Mexico and New Mexico (Table I). Large numbers of sporulated oocysts of 6 distinct morphotypes of Eimeria were found and these are described below as new species.

Bandoni and Duszynski (1988) concluded that the third edition of The International Code of Zoological Nomenclature (Ride et al., 1985) permitted illustrations to be legitimate replacements for more traditional "type specimens." The Code states that, "If a nominal species-group taxon has neither holotype [Sect. a] nor lectotype [Art. 74], all the specimens of the type series are syntypes of equal value in nomenclature and collectively constitute the name-bearing type" (Art. 73[b], p. 151). Thus, photosyntype may be a reasonable term to use when a series of photomicrographs of different sporulated oocysts, representing the same new species, is submitted to a museum as part of the original publication and naming process, as we have done here. 
TABLE I. Bats from North America that were examined for coccidia.

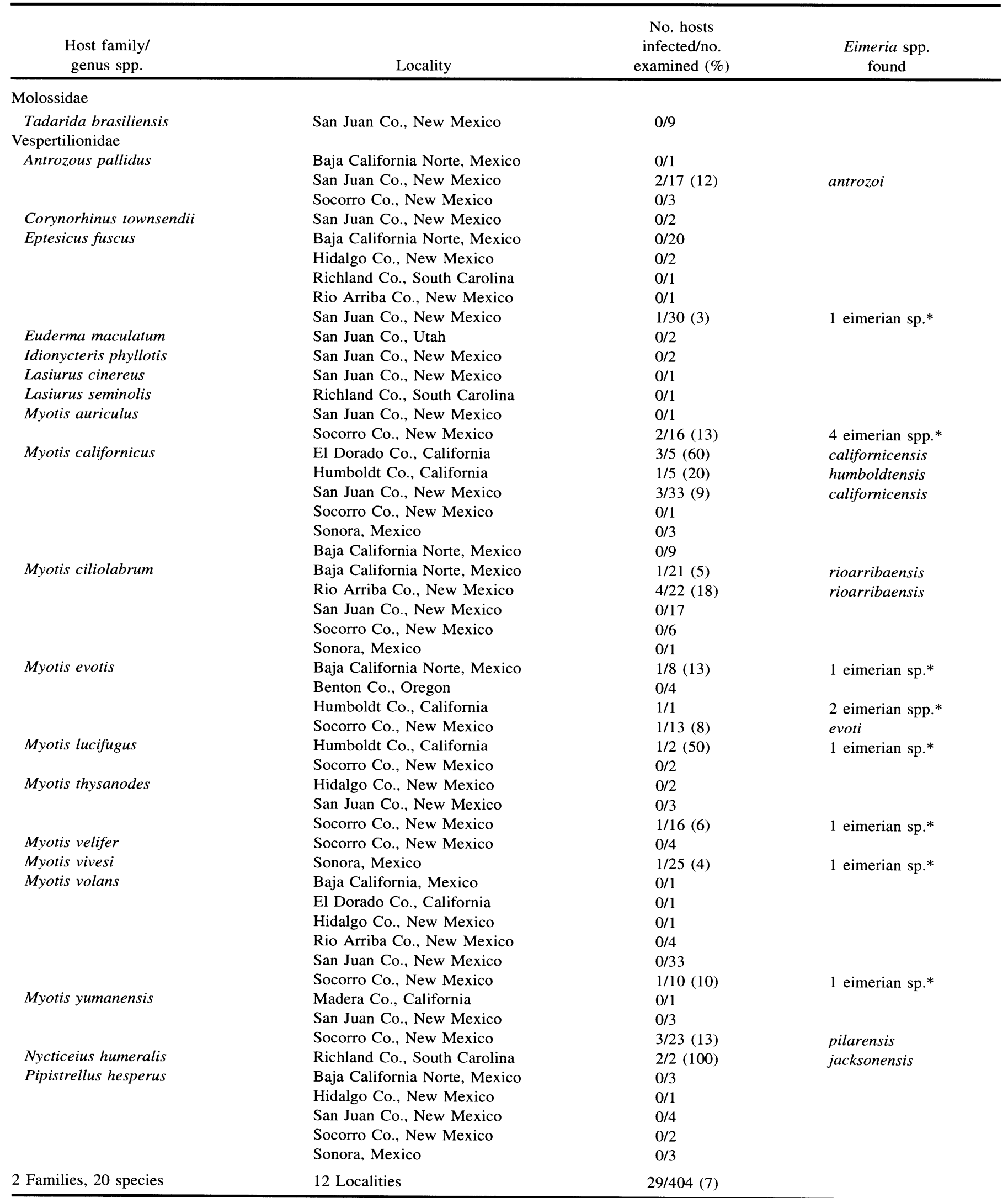

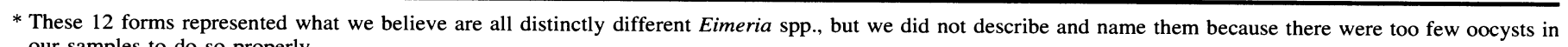
our samples to do so properly. 


\section{Eimeria californicensis n. sp.}

(Figs. 1-3, 19)

Diagnosis: Oocyst wall 1.3-1.5 thick, consisting of 2 layers: outer rough $\sim 2 / 3$ of total thickness; inner, dark, smooth; oocyst residuum and micropyle absent, but 1-7 tiny polar granules present; sporulated oocysts $(\mathrm{n}=41)$ spheroidal to subspheroidal, $19-23 \times 16-20(20.7 \times$ 18.2 ), with $\mathrm{L}$ :W ratio $1.0-1.3$ (1.1); sporocysts ovoidal, $10-12 \times 7-8$ $(11.2 \times 7.3)$, with $\mathrm{L}: \mathrm{W}$ ratio $1.4-1.7$ (1.6); pointed Stieda body present, but sub- and parastieda bodies absent. Sporocyst residuum of 4-8 medium-sized granules between the sporozoites or along 1 wall of sporocyst. Sporozoites with a distinct posterior refractile body.

\section{Taxonomic summary}

Symbiotype host: Myotis californicus (Audubon and Bachman, 1842), California myotis.

Type locality: U.S.A., California, El Dorado Co., $9.7 \mathrm{~km}$ east of Somerset.

Other localities: U.S.A., New Mexico, San Juan Co., 36 $52^{\prime} 09^{\prime \prime} \mathrm{N}$, $107^{\circ} 41^{\prime} 22^{\prime \prime} \mathrm{W}$.

Prevalence: Three of five (60\%) El Dorado Co., California; 3/33 (9\%) San Juan Co., New Mexico.

Site of infection: Unknown; oocysts collected from feces.

Material deposited: Photosyntypes of sporulated oocysts in the USNPC no. 88096. Symbiotype host: $M$. californicus, MSB 40654 (NK 576, 10 June 1979)

Etymology: The nomen triviale is derived from the state from which the host was collected and -ensis (L., belonging to).

\section{Remarks}

Using the dichotomous key of Scott and Duszynski (1997), sporulated oocysts of E. californicensis are most similar to those of Eimeria eumopos Marinkelle, 1968 in that they both have Stieda bodies but lack a micropyle, substieda body, and oocyst residuum. They differ from $E$. eumopos by being smaller $(21 \times 18$ vs. $35 \times 28)$, having a thinner oocyst wall (1.5 vs. 1.9$)$ without radial striations, and by having smaller and more numerous polar granules. Eimeria californicensis differs from other Eimeria spp. described from Myotis as follows: (1) Eimeria catronensis Scott and Duszynski, 1997 is ellipsoidal and has a micropyle; (2) E. pilarensis is small and spheroidal $(15.0 \times 14.1)$ with a smooth outer oocyst wall; and (3) Eimeria kunmingensis Yang-Xian and FuQiang, 1983 is smaller $(17.5 \times 16)$ and has a smooth outer wall.

\section{Eimeria humboldtensis n. sp.}

$$
\text { (Figs. 4-6, 20) }
$$

Diagnosis: Oocyst wall 1.5 thick, consisting of 2 layers: outer, rough $\sim 2 / 3$ of total thickness; inner, dark; oocyst residuum a large globule up to 9, but sometimes 2-3 smaller globules $\sim 3$ each; micropyle absent, but 1 polar granule present; sporulated oocysts $(n=50)$ spheroidal to subspheroidal, $20-26 \times 19-23(23.1 \times 20.7)$, with $\mathrm{L}: \mathrm{W}$ ratio $1.0-1.3$ (1.1); sporocysts ovoidal, $11-14 \times 7-8(12.5 \times 7.2)$, with $\mathrm{L}$ :W ratio 1.5-2.0 (1.7); Stieda body present, but sub- and parastieda bodies absent. Sporocyst residuum composed of small granules or globules, often as a compact mass, but sometimes dispersed along edge of sporocyst. Sporozoites with a large, posterior refractile body.

\section{Taxonomic summary}

Symbiotype host: Myotis californicus (Audubon and Bachman, 1842), California myotis.

Type locality: U.S.A., California, Humboldt Co., $12.8 \mathrm{~km}$ north, 2.4 $\mathrm{km}$ east of Arcada.

Prevalence: One in five $(20 \%)$.

Site of infection: Unknown; oocysts collected from feces.

Material deposited: Photosyntypes of sporulated oocysts in the
USNPC no. 88100 . Symbiotype host: $M$. californicus, MSB 40676 (NK 623, 13 June 1979).

Etymology: The nomen triviale is derived from the name of the county in California from which the host was collected and -ensis (L., belonging to).

\section{Remarks}

Using the dichotomous key of Scott and Duszynski (1997), sporulated oocysts of $E$. humboldtensis are most similar to those of Eimeria redukeri Duszynski, 1997, from a pipistrelle from Japan, in size and in that they both have a rough outer wall, oocyst residuum, polar granule, and Stieda body. They differ, however, in host and geographic distribution and because the oocyst wall in $E$. redukeri is heavily mammilated causing a striated appearance, whereas the wall in $E$. humboldtensis, although rough, does not have the striated appearance. Also, the oocyst residuum of $E$. redukeri is a single globule, 2-4, whereas in $E$. humboldtensis it is larger, $\sim 9$, or as $2-3$ globules $\sim 3$ each. This species differs from the previous Eimeria spp. described from Myotis as follows: (1) E. catronensis is ellipsoidal and smaller and has a micropyle; (2) E. pilarensis $(15 \times 14)$ and E. kunmingensis $(17.5 \times 16)$ are smaller and both have smooth outer oocyst walls; and (3) E. californicensis lacks an oocyst residuum.

\section{Eimeria rioarribaensis $\mathrm{n}$. sp. \\ (Figs. 7-9, 21)}

Diagnosis: Oocyst wall $\sim 1.5$ thick, consisting of 2 layers: outer, yellowish, rough $\sim 2 / 3$ of total thickness; inner, dark, smooth; micropyle and oocyst residuum are absent, but 1-2 polar granules present, $\sim 2$ each; sporulated oocysts $(\mathrm{n}=50)$ spheroidal to subspheroidal, 18-27 $\times 17-23(24.9 \times 20.1)$, with $\mathrm{L}: \mathrm{W}$ ratio $1.1-1.3(1.2)$; sporocysts ellipsoidal, $8-14 \times 7-10(12.5 \times 9.0)$, with L:W ratio $1.2-1.5(1.4)$; Stieda body $\sim 1.5$ wide, substieda body $\sim 2-3$ wide, but parastieda body is absent. Sporocyst residuum consists of 8-10 globules, often dispersed along edge of sporocyst. Sporozoites with an elongate refractile body in their posterior half.

\section{Taxonomic summary}

Type host: Myotis ciliolabrum (Audubon and Bachman, 1942), western small-footed myotis.

Type locality: U.S.A., New Mexico, Rio Arriba Co., Quintana Tank, $36^{\circ} 36^{\prime} \mathrm{N}, 107^{\circ} 23^{\prime} \mathrm{W}$, elevation 2,040 .

Other localities: Mexico, Baja California Norte, $3.2 \mathrm{~km}$ northeast of Rosarito.

Prevalence: Four of 22 (18\%) in New Mexico; 1/21 (5\%) in Mexico.

Site of infection: Unknown; oocysts collected from feces.

Material deposited: Photosyntypes of sporulated oocysts in the USNPC no. 88107. Type host: Myotis ciliolabrum, NK 27915, 13 June 1995 (animal released).

Etymology: The nomen triviale is derived from the name of the county in New Mexico where the host was collected and -ensis (L., belonging to).

\section{Remarks}

Using the dichotomous key of Scott and Duszynski (1997), sporulated oocysts of $E$. rioarribaensis are structurally most similar to those of Eimeria macyi Wheat, 1975, in that they both have a rough outer wall, Stieda and substieda bodies and polar granules, and both lack an oocyst residuum. They differ, however, in that E. rioarribaensis is larger $(25 \times 20$ vs. $19 \times 18)$ with a 2 -layered wall (vs. 1$)$ that is thicker $(1.5$ vs. 1). This species differs from the previously described Eimeria spp. from Myotis in that (1) E. catronensis is ellipsoidal and smaller and has a micropyle; $(2)$ E. pilarensis $(15 \times 14)$ and E. kunmingensis $(17.5 \times$ 16) are smaller and both have smooth outer oocyst walls; and (3) $E$. californicensis and E. humboldtensis lack a substieda body.

FiguREs 1-12. Photomicrographs of sporulated oocysts, taken under brightfield and Nomarski optics, of new Eimeria spp. from bats in North America $(\times 2,400)$. Figs. 1-3. Eimeria californicensis from Myotis californicus. Figs. 4-6. Eimeria humboldtensis from M. californicus. Figs. $7-$ 9. Eimeria rioarribaensis from Myotis ciliolabrum. Figs. 10-12. Eimeria jacksonensis from Nycticeius humeralis. 

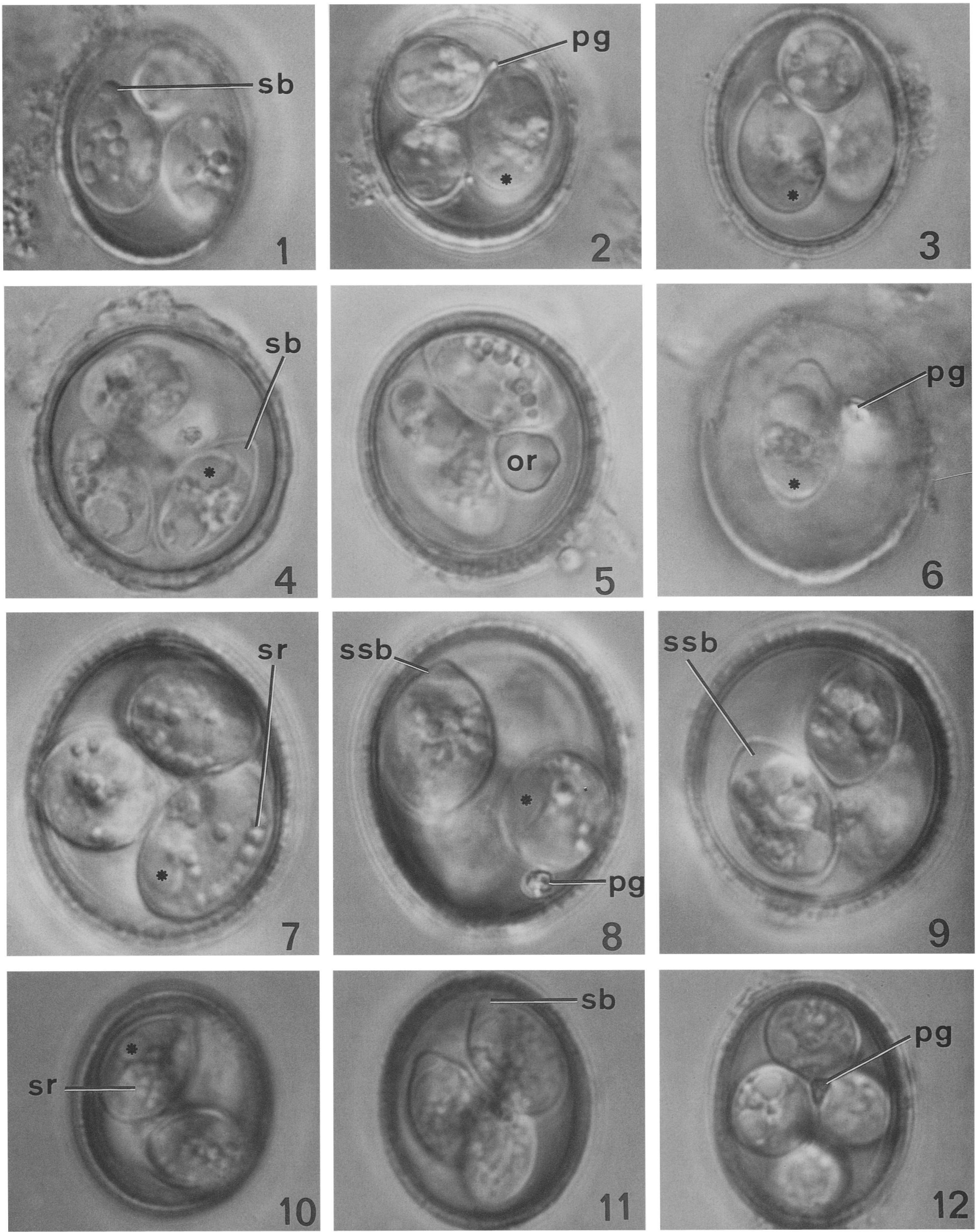

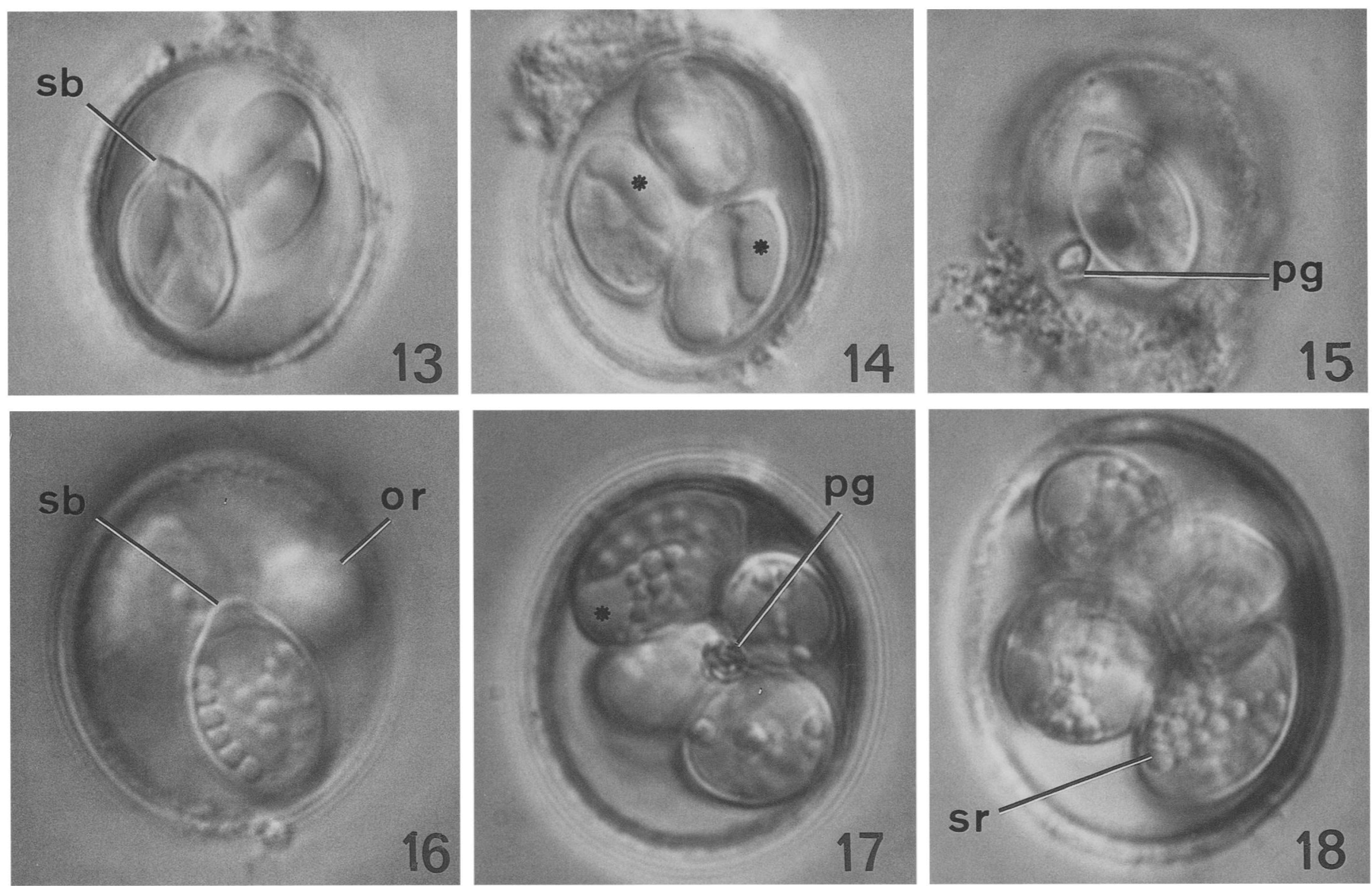

FIGURES 13-18. Photomicrographs of sporulated oocysts of new Eimeria spp. from bats in North America $(\times 2,400)$. Figs. 13-15. Eimeria evoti from Myotis evotis. Figs. 16-18. Eimeria antrozoi from Antrozous pallidus. Abbreviations for all photomicrographs: or, oocyst residuum; pg, polar granule; sb, Stieda body; sr, sporocyst residuum; ssb, substieda body; *, refractile body of sporozoite.

\section{Eimeria jacksonensis n. sp.}

(Figs. 10-12, 22)

Diagnosis: Oocyst wall 1.3-1.5 thick, consisting of 2 layers of equal thickness: outer, yellowish, mammilated; inner, dark, smooth; micropyle and oocyst residuum absent, but 1-3 polar granules present; sporulated oocysts $(\mathrm{n}=50)$ subspheroidal, $21-24 \times 17-20(22.4 \times 18)$, with $\mathrm{L}$ : $\mathrm{W}$ ratio 1.1-1.5 (1.3); sporocysts ovoidal, $9-12 \times 6-8(10.9 \times 7.7)$, with L:W ratio 1.2-1.6 (1.4); Stieda body present, but sub- and parastieda bodies absent. Sporocyst residuum composed of a granular mass sometimes obscuring sporozoites. Sporozoites appear to have at least 1 refractile body that is located either at the end or in the middle of the zoite.

\section{Taxonomic summary}

Host: Nycticeius humeralis Rafinesque, 1818.

Type locality: U.S.A., South Carolina, Richland Co., Fort Jackson, South Carolina Army National Guard Leesburg Training, Red Diamond Road Bridge over Colonel's creek.

Prevalence: Two of two (100\%).

Site of infection: Unknown; oocysts collected from feces.

Material deposited: Photosyntypes of sporulated oocysts in the USNPC no. 88101. Host released after it was measured and identified and its feces was collected.
Etymology: The nomen triviale is derived from (Fort) Jackson where the hosts were collected and -ensis (L., belonging to).

\section{Remarks}

This is the first Eimeria sp. to be described from Nycticeius. The sporulated oocysts of this species are most similar to those of $E$. macyi, E. rioarribaensis, E. eumopos, and E. californicensis in that they all have rough-walled oocysts and all lack an oocyst residuum. However, $E$. macyi and E. rioarribaensis have substieda bodies that $E$. jacksonensis lacks and E. eumopos is much larger than E. jacksonensis $(35 \times 28$ vs. $22 \times 18)$ and has a thicker oocyst wall (1.9 vs. 1.4$)$. The differences between oocysts of this species and those of $E$. californicensis are very subtle. In addition to host genus and geographic separation, the number and size of the polar granules differ between the $2 \mathrm{spp}$. as do the L/W ratios of their oocysts and granulation, size and distribution of their sporocyst residua.

\section{Eimeria evoti n. sp.}

(Figs. 13-15, 23)

Diagnosis: Oocyst wall $\sim 1.2$ thick, consisting of 2 layers: outer, yellowish, lightly pitted $\sim 2 / 3$ of total thickness; inner, smooth; micropyle and oocyst residuum absent, but 1 highly refractile polar granule present, $\sim 3$; sporulated oocysts $(n=46)$ subspheroidal, $20-24 \times 15-20$

FIGURES 19-24. Line drawings of sporulated oocysts of Eimeria californicensis (19), Eimeria humboldtensis (20), Eimeria rioarribaensis (21), Eimeria jacksonensis (22), Eimeria evoti (23), and Eimeria antrozoi (24). Scale bar $=10 \mu \mathrm{m}$. 

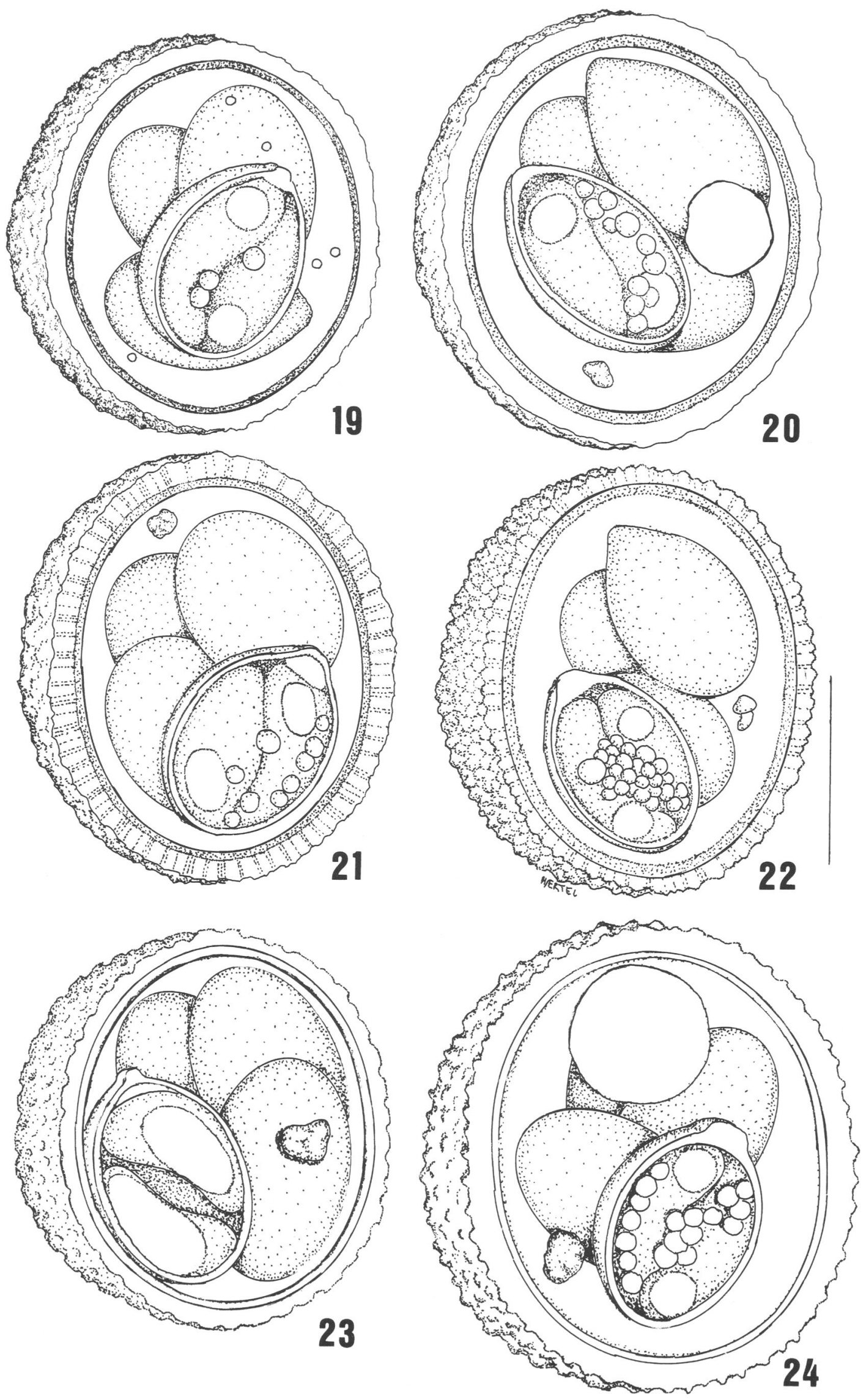
$(21.3 \times 18.6)$, with $\mathrm{L}: \mathrm{W}$ ratio $1.1-1.3(1.2)$; sporocysts ovoidal, $11-13$ $\times 7.5-9(12.2 \times 8.0)$, with $\mathrm{L}: \mathrm{W}$ ratio $1.4-1.7$ (1.5); small, nipple-like Stieda body present, as is a thin, difficult to see, substieda body that is about $2-3 \times$ wider than the Stieda body, but a parastieda body is absent. Sporocyst residuum absent. Sporozoites clearly seen with 1 elongate refractile body that composes $1 / 2$ their length.

\section{Taxonomic summary}

Host: Myotis evotis (H. Allen, 1864), gleaning myotis.

Type locality: U.S.A., New Mexico, Socorro Co., San Mateo Mountains, Bear Trap Canyon.

Prevalence: One of $13(8 \%)$.

Site of infection: Unknown; oocysts collected from feces.

Material deposited: Photosyntypes of sporulated oocysts in the USNPC no. 88099. Symbiotype host: M. evotis, MSB 53788 (NK 4803, 13 September 1980).

Etymology: The nomen triviale is derived from the specific epithet of the type host in the genitive singular ending meaning "of evotis."

\section{Remarks}

Although M. evotis has been surveyed once before for coccidia (Scott and Duszynski, 1997), no Eimeria spp. have been described previously from this host. The outer oocyst wall is neither rough and mammilated nor smooth, so it does not resemble any of the oocysts in the key provided by Scott and Duszynski (1997). In addition, the unique combination of structural features (pitted outer wall), tiny Stieda body, or their absence (neither oocyst nor sporocyst resuduum) distinguish the sporulated oocysts of this species from all those described previously from bats.

\section{Eimeria antrozoi n. sp. \\ (Figs. 16-18, 24)}

Diagnosis: Oocyst wall 1.2-1.5 thick, consisting of 2 layers; outer, strongly sculptured, $\sim 3 / 4$ of total thickness; inner, smooth; micropyle absent; oocyst residuum usually a large lipid-like sphere, $\sim 8$, but sometimes $2-3$ smaller spheres; 1 highly refractile polar granule present, $\sim 3$; sporulated oocysts $(\mathrm{n}=78)$ subspheroidal, $22-27 \times 19-24(24.8 \times$ 21.6), with L:W ratio 1.0-1.3 (1.15); sporocysts ovoidal, 9-13 $\times 7-10$ $(11.5 \times 7.8)$, with L:W ratio $1.2-1.7$ (1.5); prominent Stieda body present, $\sim 3$ wide, but sub- and parastieda bodies absent. Sporocyst residuum of many large granules sometimes obscuring sporozoites. Sporozoites with 1 round, refractile body at their rounded end.

\section{Taxonomic summary}

Type host: Antrozous pallidus Le Conte, 1854, pallid bat.

Type locality: U.S.A., New Mexico, San Juan Co., Upper Pump Canyon, near Twin Tanks, $36^{\circ} 51^{\prime} 80^{\prime \prime} \mathrm{N}, 107^{\circ} 47^{\prime} 40^{\prime \prime} \mathrm{W}$.

Other localities: See Scott and Duszynski, 1997 (=Eimeria arizonensis-like).

Prevalence: Two of $17(12 \%)$

Site of infection: Unknown; oocysts collected from feces.

Material deposited: Photosyntypes of sporulated oocysts in the USNPC no. 88094. Type host: Antrozous pallidus, NK 41192, 10 July 1996 (animal released).

Etymology: The nomen triviale is derived from the generic name of the host in the genitive singular ending meaning "of Antrozous."

\section{Remarks}

These sporulated oocysts first were reported in 12/85 (14\%) pallid bats from 2 of 5 collection localities in New Mexico and Mexico by Scott and Duszynski (1997); they declined to name it at the time because of the similarity of these oocysts to those of E. arizonensis, a known parasite of rodents. They suggested naming of this form be delayed until cross-infection and/or molecular studies are completed to demonstrate 2 distinct species. However, the regularity and the high prevalence in some bat populations strongly suggest this is not a spurious infection; it now has been found in 14/36 (39\%) pallid bats from 2 counties in New Mexico (6/11, 55\%, Eddy Co.; 2/17, 12\%, San Juan Co.) and in Baja California Sur, Mexico $(6 / 8,75 \%)$, but not in 66 palid bats from Bernalillo, Sandoval, or Lincoln counties in New Mexico (Scott and Duszynski, 1997; present study). Using the key to previously described Eimeria from bats (Scott and Duszynski, 1997), E. antrozoi is structurally most similar to Eimeria tomopea Duszynski and Barkley, 1985 and to E. redukeri Duszynski, 1997. It differs from the former by having smaller oocysts $(25 \times 22$ vs. $31 \times 25)$ and sporocysts $(11.5 \times$ 8 vs. $14 \times 9$ ) and in having a large, prominent Stieda body versus one that is not easily seen unless the sporocysts are freed from the oocyst. It differs from $E$. redukeri by having a thicker oocyst wall (1.5 vs. 1), larger oocysts $(25 \times 22$ vs. $20 \times 18)$ and a wide, conspicuous Stieda body, and by having a prominent sporocyst residuum of many large granules versus one with only $1-3$ spheroids.

\section{DISCUSSION}

Currently, there are only 9 named Eimeria spp. described from bats in North America, including the 6 described in this paper (Duszynski et al., 1988; Scott and Duszynski, 1997). Although there were too few sporulated oocysts to make adequate, complete descriptions (as per Duszynski and Wilber, 1997), we saw oocysts that probably represent another 12 species (Table I); also, only a small portion of the U.S.A. (6 states) and Mexico (3 states) have been surveyed for bat coccidia, with no work done yet in Canada or Alaska (Duszynski et al., 1988; Scott and Duszynski, 1997; Wheat, 1975). Thus, the number of $E i$ meria spp., at least in bat species living between Alaska and Mexico, could increase rapidly if more surveys to look for them are done. Collection of feces during such surveys can be conducted easily by anyone who captures and handles bats for any purpose. Therefore, as more mammalogists (chiropterologists) are convinced about the information value that knowledge of the coccidia from bats may provide (new species, coevolution studies, host specificity), the more likely we will see an explosion in the descriptions of bat coccidia.

Given the direct life cycle of most Eimeria spp., in which unsporulated oocysts leave the host in the feces and then need (at least) moisture, protection from UV radiation, and oxygen to be able to sporulate in the external environment, bats most likely to be infected with the new generation of oocysts are those that roost in large, permanent colonies. Unfortunately, however, Tadarida brasiliensis, which forms large colonies, have not been positive for coccidia in previous studies (Scott and Duszynski, 1997). Behaviors such as self- and allogrooming, nursing, and copulation may increase the likelihood of contact with oocysts, whereas behaviors such as solitary roosting and roost switching may decrease the chance of contact with oocysts. In addition, microclimate, e.g., relative humidity, temperature, or roost structure, e.g., tight spaces such as crevices, open caves, tree holes, etc., or both, may also impact the successful transmission of Eimeria spp. in ways we do not yet understand. Therefore, as we learn more about the eimeriid parasites found in bats, this knowledge could assist our understanding of the basic ecology of bats.

Two of the Eimeria spp. in bats seem to be widely distributed with their hosts: E. californicensis, found in M. californicus from California and New Mexico and E. antrozoi, in A. pallidus from New Mexico and Baja California Norte, Mexico. The California myotid is often found in trees, shrubs, rock crevices, and even on rocks near the ground, but it will roost wherever it is convenient (Brigham et al., 1997; Hirshfeld et al., 1977; Krutzsch, 1954). This roosting behavior may not seem conducive to parasite transmission, but other factors may play a role in this infection cycle. For example, females of $M$. californicus, $M$. ciliolabrum, and $N$. humeralis (infected bats in this study) 
form small nursery colonies in June (Krutzsch, 1954; Wilkin son, 1998), which may increase the likelihood of oocyst contact via nursing, grooming, and allogrooming. Also, Wilkinson (1998) reported that evening bats, $N$. humeralis, conduct com munal nursing, which also may increase the probability of contact with sporulated oocysts. Interestingly, all of these infected bats in this study were females collected in mid-June. Thus $\rightarrow$ nursery colonies for these species may play an important role in the life cycle of their eimerian parasites. Similarly, pallid bats, $A$. pallidus, are quite social, generally found in fairly large colonies, and like their myotid relatives, females form maternity colonies, but with the males also found in or near these colo nies. Pallid bats are often found roosting in buildings and in warm rock shelters and caves from which they emerge in the evenings to forage. They fly close to the desert surface, and occasionally land to capture terrestrial invertebrates, e.g., scorpions, and vertebrates, e.g., lizards, pocket mice (Findley, 1987, 1993). The combination of these behaviors likely is important to maintaining their eimerian parasite fauna.

\section{ACKNOWLEDGMENTS}

We are grateful to Lee Couch for reviewing earlier drafts of this manuscript, to Lynn Hertel for the line drawings, to Xiaomin Zhao for his assistance in the dark room, and to Bryan Hall, Mary Strayer Bunch, Andy Deans, and William Gannor for their assistance in the field. This work was supported, in part, by the Department of Defense Legacy Program through the National Guard Bureau, South Carolina Army National Guard and the South Carolina Department of Natural Resources Wildlife Diversity Section; in part, by the New Mexico Department of Game and Fish, Share with Wildlife, Bureau of Land Management, and U.S. Forest Service (Lincoln and Gila National Forest) contracts to W.L. Gannon; and, in part, by an NSF-PEET grant (DEB-9521687) to D.W.D.

\section{LITERATURE CITED}

BANDONI, S., AND D. W. DuszYnSKi. 1988. A plea for improved presentation of type material for coccidia. Journal of Parasitology 74: 519-523.
Brigham, R. M., M. J. Vonhof, R. M. R. Barclay, and J. C. Gwilliam. 1997. Roosting behavior and roost-site preferences of forest-dwelling California bats (Myotis californicus). Journal of Mammalogy 78: $1231-1239$.

$\rightarrow$ DuszYnSKI, D. W. 1997. Coccidia from bats (Chiroptera) of the world: A new Eimeria species in Pipistrellus javanicus from Japan. Journal of Parasitology 83: 280-282.

$\rightarrow-$ D. W. Reduker, ANd B. B. PARKer. 1988. Eimeria from bats of the world. A new species in Tadarida femorosacca from Sonora, Mexico. Journal of Parasitology 78: 930-932.

$\rightarrow-$ D. T. SCOTT, AND X. ZHAO. 1999. Eimeria from bats of Bolivia: Two new species from vespertilionid bats. Journal of Parasitology 85: 504-507.

- AND P. G. WILBER. 1997. A guideline for the preparation of species descriptions in the Eimeriidae. Journal of Parasitology 83: 333-336.

FINDLEY, J. S. 1987. The natural history of New Mexico mammals. The University of New Mexico Press, Albuquerque, New Mexico, p. 35-48.

1993. Bats. A community perspective. Cambridge University Press, Cambridge, U.K., p. 16.

$\rightarrow$ Frey, J. K., T. L. Yates, D. W. Duszynski, W. L. Gannon, and S. L. GARDNER. 1992. Designation and curatorial management of type host specimens (symbiotypes) for new parasite species. Journal of Parasitology 78: 930-932.

Hirshreld, J. R., Z. C. Nelson, AND W. G. Bradley. 1977. Night roosting behavior in four species of desert bats, The Southwestern Naturalist 22: $427-433$.

KruTZSCH, J. M. 1954. Notes on the habits of the bats, Myotis californicus. Journal of Mammalogy 35: 539-545.

LEVINE, N. D., AND V. IVENS. 1990. The coccidian parasites of rodents. CRC Press, Boca Raton, Florida, 228 p.

Ride, W. D. L., C. W. Sabrosky, G. Bernardi, and R. V. Melville (eds.). 1985. International code of zoological nomenclature, 3rd ed. H. Charlesworth and Co., Ltd., Huddersfield, England, 339 p.

$\rightarrow$ SCOTT, D. T., AND D. W. DuszYNSKI. 1997. Eimeria from bats of the world: Two new species from Myotis spp. (Chiroptera: Vespertilionidae). Journal of Parasitology 83: 495-501.

$\rightarrow$ WheAt, B. E. 1975. Eimeria macyi sp. n. (Protozoa: Eimeriidae) from the eastern pipistrelle, Pipistrellus subflavus, from Alabama. Journal of Parasitology 61: 920-922.

Wilkinson, G. S. 1998. Communal nursing in the evening bat, Nycticeius humeralis. Behavioral Ecology and Sociobiology 31: 225235 . 